\title{
Inactivation of Factor XIa by Plasma Protease Inhibitors
}

\author{
PREDOMINANT ROLE OF $\alpha_{1}$-PROTEASE INHIBITOR AND PROTECTIVE \\ EFFECT OF HIGH MOLECULAR WEIGHT KININOGEN
}

\author{
Cheryl F. Scott, Marc Schapira, Harold L. James, Allen B. Cohen, and \\ ROBERT W. Colman, Thrombosis Research Center and Hematology-Oncology \\ and Pulmonary Sections of the Department of Medicine, Temple University \\ Health Sciences Center, Philadelphia, Pennsylvania 19140
}

A B STRACT Factor XIa is a plasma protease that, by activating Factor IX, plays an important role in the early phase of the intrinsic pathway of blood coagulation. Four plasma protease inhibitors, $\alpha_{1}$-protease inhibitor, antithrombin III, C1-inhibitor, and $\alpha_{2}$-plasmin inhibitor, have been reported to inactivate human Factor XIa, but their quantitative contribution to the inactivation of Factor XIa in plasma has not been fully assessed. Using purified systems, we observed that the second-order rate constants for the reaction of Factor $\mathrm{XIa}$ with $\alpha_{1}$-protease inhibitor, antithrombin III, and CI-inhibitor were $4.08,10$, and $14.6 \mathrm{M}^{-1} \mathrm{~min}^{-1} \times 10^{3}$, respectively. The pseudo-first-order rate constants, at plasma concentration of the inhibitors, were 1.86 $\times 10^{-1}, 4.68 \times 10^{-2}$, and $2.4 \times 10^{-2} \mathrm{~min}^{-1}$, respectively. These kinetic data predict that $\alpha_{1}$-protease inhibitor should account for $68 \%$, antithrombin III for $16 \%$, and $\mathrm{Cl} 1$-inhibitor and the equipotent $\alpha_{2}$-plasmin inhibitor each for $8 \%$ of the total inhibitory activity of plasma against Factor XIa. The rate of inactivation of Factor $\mathrm{XIa}$ in various plasma samples specifically deficient in inhibitors was consistent with these predictions.

Factor XI, the zymogen form of Factor XIa, circulates in plasma associated with the contact system cofactor, high molecular weight kininogen (HMW kininogen). Kinetic analysis indicated the existence of a reversible bimolecular Factor XIa-HMW kininogen complex with a dissociation constant $\left(K_{\mathrm{d}}\right)=0.17 \mu \mathrm{M}$. The light chain derived from HMW kininogen decreased the inactivation rate of Factor XIa by Cl-inhibitor with a $K_{d}$ of $0.08 \mu \mathrm{M}$ for a complex of Factor $\mathrm{XIa}$ and the light chain derived from HMW kininogen. The protective effect of HMW kininogen was confirmed by the finding that the inactivation rate of Fac-

Received for publication 22 July 1981 and in revised form 19 November 1981. tor XIa in kininogen-deficient plasma was increased over normal plasma.

The present study confirms that $\alpha_{1}$-protease inhibitor is the major inhibitor of Factor XIa in plasma, and that the formation of a reversible complex between Factor XIa and HMW kininogen decreases the rate of inactivation of the enzyme by its inhibitors.

\section{INTRODUCTION}

Factor XII, prekallikrein, high molecular weight $(\mathrm{HMW})^{1}$ kininogen, and Factor XI are plasma proteins required for the in vitro initiation of blood coagulation induced by exposure to a foreign surface. Purified Factor XI, like prekallikrein, is converted to an active serine protease by activated Factor XII $(1,2)$ in the presence of the cofactor HMW kininogen (3). Since Factor XIa is the first enzyme belonging primarily to the coagulation cascade, and since a hemorrhagic state can result from its deficiency, it may play a key role in the regulation of blood coagulation. The active enzymes in the contact system, Factor XIIa, kallikrein, and Factor XIa are subject to inactivation by several plasma protease inhibitors. In the case of Factor XIa, four different plasma proteins-C1-inhibitor (4), antithrombin III (5), $\alpha_{1}$-protease inhibitor ( $\alpha_{1}$-antitrypsin) (6), and $\alpha_{2}$-antiplasmin (7)-have been found to have inhibitory activity, whereas another plasma protease inhibitor, $\alpha_{2}$-macroglobulin (8), does not inactivate Factor XIa. A quantitative comparison of the kinetics and potency of these inhibitors has not been made in purified systems and the relative contribution of each inhibitor to the inactivation of XIa in plasma is not known. The cofactor, HMW kininogen, must also be

\footnotetext{
${ }^{1}$ Abbreviations used in this paper: HMW, high molecular weight; $\mathrm{HMWK}_{\mathrm{L}}$, light chain derived from $\mathrm{HMW}$ kininogen; LMW, light molecular weight.
} 
considered in evaluating the regulation of Factor XIa inhibition by plasma protease inhibitors. Factor XI, the zymogen of Factor XIa, prekallikrein, the precursor of plasma kallikrein, and plasma kallikrein, are each known to form a bimolecular complex with HMW kininogen (9-12). Furthermore, when plasma kallikrein forms a complex with HMW kininogen, a decrease in the inactivation rate by plasma protease inhibitors is observed (13). Since HMW kininogen is capable of protecting kallikrein from inactivation, we explored the possibility that it could also protect Factor $\mathrm{XIa}$. This study was designed to quantitate the relative contribution of the plasma protease inhibitors of Factor XIa, as well as to examine the effect of HMW kininogen on the inhibition of Factor XIa.

\section{METHODS}

\section{Plasma}

All plasma samples were collected from either healthy volunteers or factor-deficient donors into a $1 / 10 \mathrm{vol}$ of $3.8 \%$ sodium citrate in plastic containers. Written informed consent was obtained before venipuncture. Factor XI-deficient plasma, with $<0.05 \mathrm{U} / \mathrm{ml}$ Factor XI, was donated directly to us. Kininogen-deficient plasma was donated to us by Mrs. M. Williams (14). Plasma from a patient with typical symptoms of hereditary angioedema containing $9 \% \mathrm{Cl}$-inhibitor as determined by radial immunodiffusion (15), and $<5 \%$ as determined by a functional assay based on plasma kallikrein inhibition (16), was donated directly to us. $\alpha_{1}$-protease inhibitor $\left(\alpha_{1}\right.$-antitrypsin)-deficient plasma was obtained from a patient at Temple University Hospital. The trypsin inhibitory capacity of the plasma was $20 \%$ of normal pooled plasma, as determined by a functional assay (17). Plasma was rendered deficient in antithrombin III by passing the plasma over a heparin-agarose column equilibrated with 20 $\mathrm{mM}$ Tris $\mathrm{Cl}$ buffer, $\mathrm{pH} 7.5$, containing $0.15 \mathrm{M} \mathrm{NaCl}$ (18). As assessed by radial immunodiffusion, the residual antithrombin III was $<5 \%$ of normal pooled plasma. Normal plasma was purchased from George King Biomedicals Inc., Overland Park, KS, as a pool of 20 normal donors' plasma.

\section{Inhibitors}

$\alpha_{1}$-protease inhibitor. This was prepared by the method of Cohen and James (19). $1 \mathrm{mg}$ of this preparation completely inhibited $0.44 \mathrm{mg}$ of trypsin. After reduction, the protein migrated as a single band of $M_{\mathrm{r}}=54,000$ on polyacrylamide gel electrophoresis in the presence of SDS and had a single amino terminal glutamic acid by the dansyl method (20).

Antithrombin III. This was purchased from Kabi (AB), Stockholm, Sweden. It contained no measurable Factor XI or XIa activity, $\alpha_{1}$-protease inhibitor, $\alpha_{2}$-macroglobulin, or $\mathrm{Cl}$-inhibitor antigens, and appeared as a single band on SDS gel electrophoresis in the presence of $\beta$-mercaptoethanol (21).

C1-inhibitor. This was generously supplied as a partially purified preparation by Dr. Milan Wickerhauser (22). This material was subjected to chromatography on DEAE-cellulose to remove contaminating proteins. The final product was a single band of 105,000 daltons (13) on SDS gel elec- trophoresis (21) and contained no detectable Factor XI or XIa activity, $\alpha_{2}$-macroglobulin, antithrombin III, or $\alpha_{1}$-protease inhibitor antigen. The material was $97 \%$ active, according to the method of Levy and Lepow (23).

$H M W$ kininogen. This was prepared by the method of Kerbiriou and Griffin (24). The specific activity was 12 coagulant $U$ (14)/mg protein (25). A single band of 110,000 daltons was observed on SDS gel electrophoresis (21) with or without $\beta$-mercaptoethanol. It contained no detectable Factor XI or XIa activity. The light chain from HMW kininogen $\left(\mathrm{HMWK}_{\mathrm{L}}\right.$ ) was prepared by digestion of the HMW kininogen with plasma kallikrein, reduction, alkylation, and isolation, according to the method of Kerbiriou and Griffin (24). It was a single band of $M_{r}=45,000$ on SDS gel electrophoresis (26) with a specific activity of 30 coagulant $\mathrm{U} / \mathrm{mg}$ of light chain. It should be noted that the coagulant activity per mole of light chain is identical to the intact HMW kininogen, in agreement with Kerbiriou and Griffin (24).

Factor XI. This was prepared essentially according to the method of Scott et al. (27) for isolating prekallikrein. When the gamma globulins from plasma were subjected to SPSephadex chromatography at pH 8.1, the Factor XI bound more tightly than the prekallikrein $(6,25)$. The Factor XIrich fractions were then pooled, concentrated, dialyzed, and applied to a second SP-Sephadex column, pH 5.3, identical to the column used for prekallikrein isolation (27). The Factor XI-rich fractions from that column were then concentrated and dialyzed vs. $10 \mathrm{mM}$ sodium acetate, pH 5.3, containing $0.15 \mathrm{M} \mathrm{NaCl}$. The final step in the purification of Factor XI was the removal of immunoglobulin (Ig) $G$ by batch adsorption to $1 \mathrm{ml}$ of anti-IgG-agarose that had been equilibrated in $0.1 \mathrm{M}$ Tris- $\mathrm{Cl}, \mathrm{pH} 8.0$, containing $0.15 \mathrm{M}$ $\mathrm{NaCl}$. Factor XI $(0.4 \mathrm{ml}$ of a stock of $90 \mathrm{U} / \mathrm{ml})$ was diluted $1: 2$ with buffer and then mixed with the $1 \mathrm{ml}$ of equilibrated gel in a microcentrifuge tube $(1.5-\mathrm{ml}$ capacity) for $5 \mathrm{~min}$. The sample was then centrifuged at room temperature for 2 min. After this procedure, IgG could not be detected by radial immunodiffusion on L-C partigen plates (Behring Diagnostics, Inc., Somerville, NJ). The supernate contained $40 \mathrm{U} / \mathrm{ml}$ Factor XI activity (sp act $=203 \mathrm{U} / \mathrm{mg}$ ). Yields between 40 and $55 \%$ of the original plasma concentration were repeatedly observed. No prekallikrein or Factor XII activity was detected by coagulation assay. The plasma concentration of Factor $\mathrm{XI} \cong 0.03 \mu \mathrm{M}$ based on a $M_{\mathrm{r}}=160,000$ and a protein concentration of $4 \mu \mathrm{g} / \mathrm{ml}$.

Low molecular weight (LMW) kininogen. We purified LMW kininogen from plasma by a modification of the method of Habal et al. (28), using chromatography on QAE Sephadex, ammonium sulfate precipitation, and gel filtration through Ultragel AcA 34 instead of Sephadex G200. LMW kininogen eluted with $0.12 \mathrm{M} \mathrm{NaCl}$ on the first step and had no HMW kininogen coagulant activity, but it reacted with an antibody against kininogen. The antibody was prepared against HMW kininogen in a rabbit and adsorbed with kininogen-deficient plasma. A single precipitin arc was observed by immunoelectrophoresis against normal plasma, HMW kininogen, or LMW kininogen.

Fresh frozen plasma. Protein purification was performed on plasma generously supplied by the American Red Cross, Philadelphia, PA.

Other reagents. Bovine serum albumin (crystalline) was purchased from Sigma Chemical Co., St. Louis, MO; polystyrene test tubes $(10 \times 75 \mathrm{~mm})$ and polypropylene microcentrifuge tubes ( 0.5 and $1.5 \mathrm{ml}$ capacities) from Walter Sarstedt, Inc., Princeton, NJ; SDS, A5M, and molecular weight standards from Bio-Rad Laboratories, Rockville Cen- 
ter, NY; DEAE-cellulose from Whatman, Inc., Clifton, NJ: QAE Sephadex, SP-Sephadex, and G-200 from Pharmacia Fine Chemicals, Div. of Pharmacia Inc., Piscataway, NJ: Anti-IgG agarose from Miles Laboratories, Inc., Elkhart, IN: and Bolton-Hunter reagent from New England Nuclear, Boston, MA. All other reagents were of reagent grade.

Activation of Factor XI. Factor XI was activated with trypsin by the method described by Mannhalter et al. (29). The activation was monitored by the appearance of Factor XIa coagulant activity. When the Factor XI was completely activated, the trypsin was neutralized by the addition of a twofold excess of soybean trypsin inhibitor. The activated Factor XI (Factor XIa) was then chromatographed on a 1ml column of QAE-sephadex (equilibrated with $20 \mathrm{mM}$ Trischloride, $\mathrm{pH} 8.0$, containing $0.05 \mathrm{M} \mathrm{NaCl}$ ) to remove the soybean trypsin inhibitor. The breakthrough fractions contained Factor XIa activity, without appreciable dilution.

Radiolabeling of Factor XIa. Factor XIa $(40 \mu \mathrm{g} / \mathrm{ml})$ was labeled with ${ }^{125} I$ by means of the Bolton-Hunter method (30). The specific radioactivity was $20 \mu \mathrm{Ci} / \mu \mathrm{g}$. The labeled Factor XIa was gel filtered on an A5M column to remove any unbound radioactivity.

Stability of Factor XI. Factor XI or XIa was stored for $>6$ mo at $4^{\circ} \mathrm{C}$ with no loss of coagulant activity. Factors XI and XIa activity was also found to be stable in SDS between 0.1 and $1 \%$ in the absence of reducing agents. SDS could also be used to remove any Factor XI or XIa that was absorbed to the plastic storage tube.

Assay of Factors XI and XIa. Coagulant activity of Factor XI was determined with a partial thromboplastin time assay with Factor XI-deficient plasma as the substrate in the presence of kaolin (31). Factor XIa was assayed as above, with $0.15 \mathrm{M} \mathrm{NaCl}$ substituted for kaolin.

Inhibition of Factor XIa. All incubations were performed in $0.5-\mathrm{ml}$ polypropylene microcentrifuge tubes at 23 or $37^{\circ} \mathrm{C}$. To minimize both the adsorption of Factor XIa onto the test tube surface and its consequent inactivation, bovine serum albumin $(5 \mathrm{mg} / \mathrm{ml})$ was incubated in the tube for 5 min. Next, Factor XIa was added and incubated for $5 \mathrm{~min}$. HMW kininogen or buffer was then added, and, finally, inhibitor was added. At various times, $10 \mu \mathrm{l}$ was removed and assayed for Factor XIa activity as described above. The data are expressed as percentages of initial Factor XIa activity.

SDS slab gel electrophoresis. Samples were applied to $10 \%$ polyacrylamide gels $(10 \mathrm{~cm} \times 10 \mathrm{~cm} \times 1.5 \mathrm{~mm}) \mathrm{ac}-$ cording to either Laemmli (21) or Weber and Osborn (26).

\section{RESULTS}

Purity of Factor XIa. $100 \mu$ l of radiolabeled Factor $\mathrm{XIa}$, after removal of unbound radioactivity (see Methods), was chromatographed on a Bio-Rad A5M column in the presence of $0.1 \%$ SDS (Fig. 1). One major peak of radioactivity was observed, eluting with a $M_{\mathrm{r}}$ of 150,000 . Factor XIa was also electrophoresed on a slab gel (20) in the presence of SDS without a reducing agent (Fig. 1, inset). It migrated as a single band of $\sim 180,000$.

Inhibition of Factor XIa by plasma protease inhibitors. The inhibition of Factor XIa by $\alpha_{1}$-protease inhibitor, antithrombin III, or Cl-inhibitor (Fig. 2) exhibited pseudo-first-order kinetics when the inhibitor was present in a molar excess of 10 - to 100 -fold.

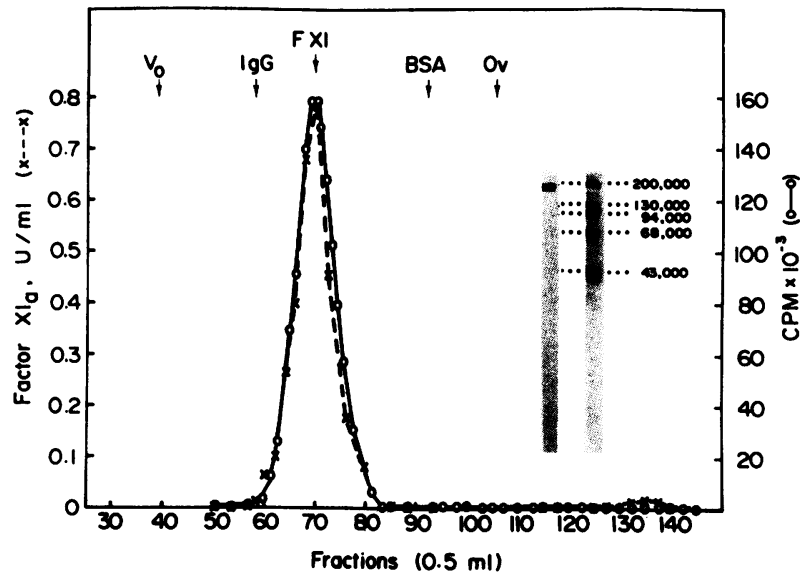

Figure 1 Purity of Factor XIa. Radiolabeled Factor XIa was chromatographed on an A5M column $(1.25 \times 57 \mathrm{~cm})$ equilibrated in $37.5 \mathrm{mM}$ Tris- $\mathrm{Cl}$, $\mathrm{pH} 8.8$, containing $0.1 \%$ SDS at $23^{\circ} \mathrm{C}$. The column was standardized with IgG, bovine serum albumin, ovalbumin, and Factor XI (assessed by coagulation activity). The inset represents Factor XIa (3 $\mu \mathrm{g})$ subjected to electrophoresis in SDS, and molecular weight standards $\left(200,130,94,68\right.$, and $\left.43 \times 10^{3}\right)$ stained with Coomassie Brilliant Blue R-250.

A linear relationship was observed between the pseudofirst-order reaction rate constant, $k^{\prime}$, and inhibitor concentration (Fig. 2, insets). Second-order rate constants $\left(k^{\prime \prime}\right)$ for the inhibition of XIa at $23^{\circ} \mathrm{C}$ were calculated from the insets of Fig. 2 and found to be $4,000\left(\alpha_{1}\right.$ protease inhibitor), 10,000 (antithrombin III), and 15,000 (Cl-inhibitor) $\mathrm{M}^{-1} \mathrm{~min}^{-1}$.

Effect of HMW kininogen on the inhibition of Factor XIa. Since HMW kininogen is known to form a complex with Factor XI, prekallikrein, and kallikrein in plasma (9-12), we tested the hypothesis that like kallikrein, Factor XI might be protected by HMW kininogen from inhibition. When various concentrations of HMW kininogen were added to Factor XIa at $23^{\circ} \mathrm{C}$, before addition of inhibitor, the rate of inhibition was decreased in a concentration-dependent fashion when compared with the inactivation rate of Factor XIa in the absence of HMW kininogen (Fig. 3). We assumed a model represented by the expression:

$$
\begin{aligned}
& \mathrm{E}+\mathrm{I} \stackrel{k^{*}}{\rightarrow} \mathrm{EI}, \\
& \mathrm{E}+\mathrm{C} \underset{k-1}{\stackrel{k_{+1}}{\rightleftharpoons}} \mathrm{EC},
\end{aligned}
$$

for the inhibition of Factor XIa in the presence of HMW kininogen (where E is Factor XIa, I is inhibitor, $\mathrm{C}$ is HMW kininogen, and EI the irreversible enzymeinhibitor complex). The second-order rate constant $\left(k^{\prime \prime}\right)$ is the reaction between $\mathrm{E}$ and $\mathrm{I}$, and the dissociation constant $\left(K_{d}\right)$ of the reversible EC complex is $k_{+1} / k_{-1}$. 

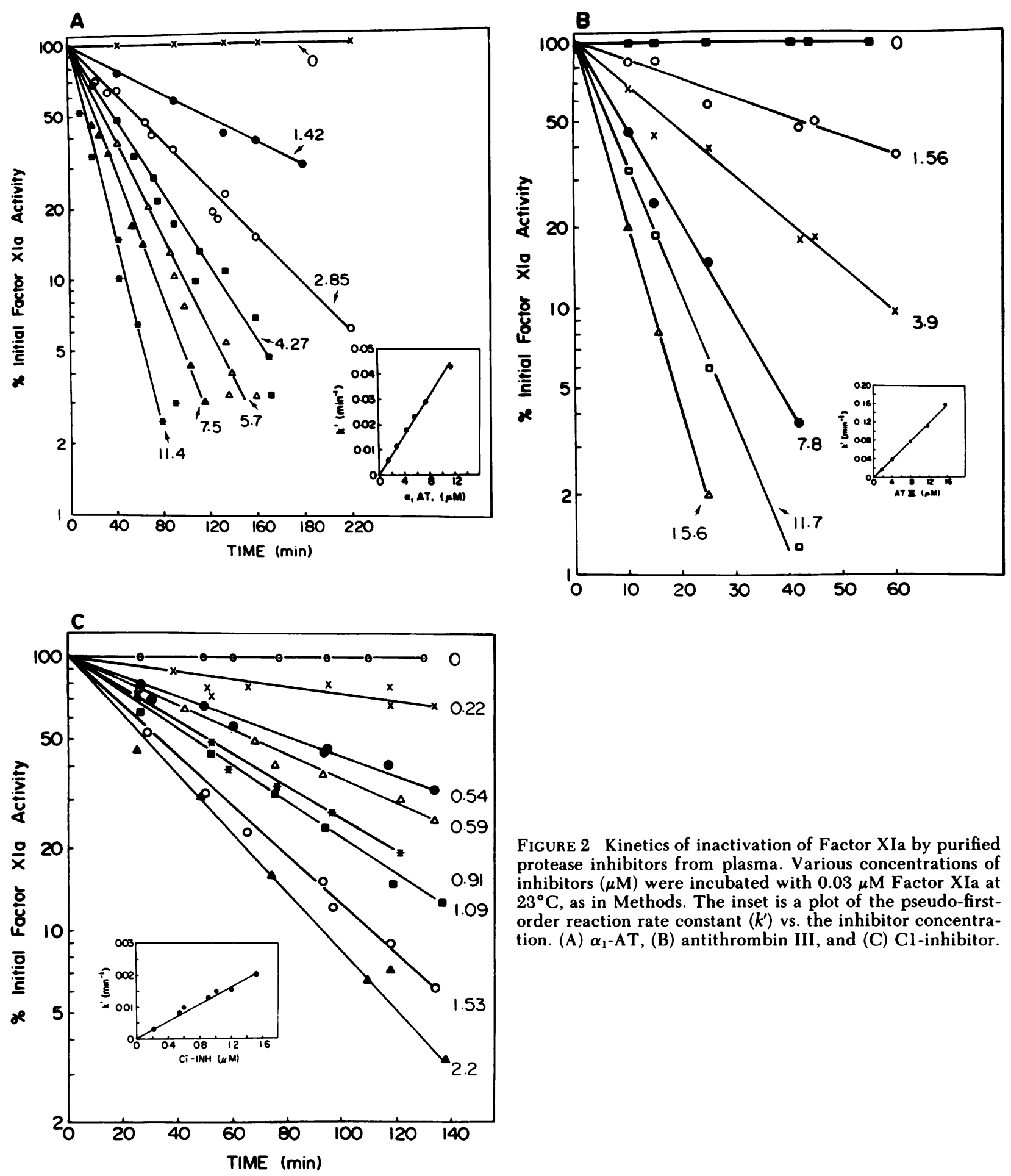

An equation can then be derived (32):

$$
k_{\mathrm{app}}^{\prime}=\frac{k^{\prime}}{1+\mathrm{C} / K_{\mathrm{d}}},
$$

FIGURE 2 Kinetics of inactivation of Factor XIa by purified protease inhibitors from plasma. Various concentrations of inhibitors $(\mu \mathrm{M})$ were incubated with $0.03 \mu \mathrm{M}$ Factor XIa at $23^{\circ} \mathrm{C}$, as in Methods. The inset is a plot of the pseudo-firstorder reaction rate constant $\left(k^{\prime}\right)$ vs. the inhibitor concentration. (A) $\alpha_{1}-\mathrm{AT}$, (B) antithrombin III, and (C) Cl-inhibitor. 

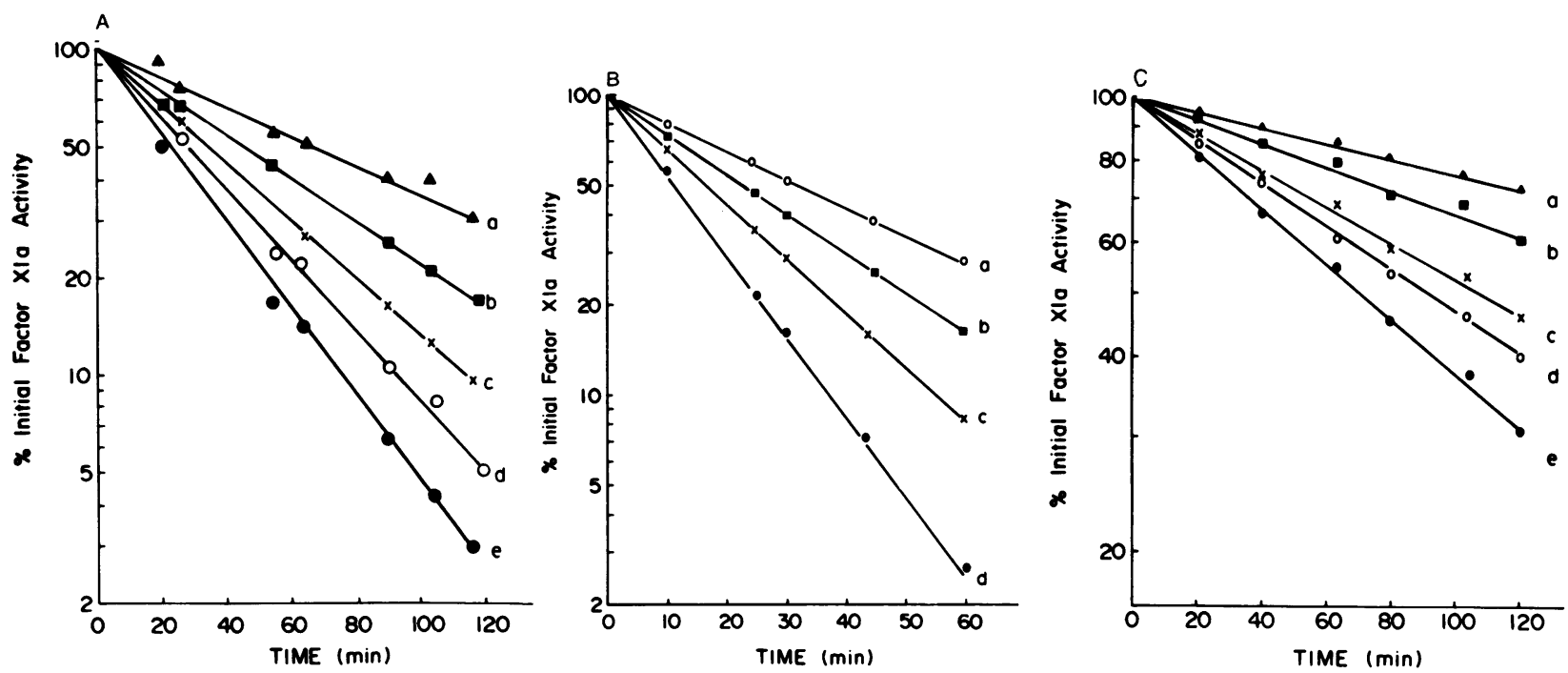

Figure 3 (A) Kinetics of inactivation of Factor XIa in the presence and absence of $\mathrm{HMW}$ kininogen. Increasing concentrations of $\mathrm{HMW}$ kininogen were incubated at $23^{\circ} \mathrm{C}$ with 0.03 $\mu \mathrm{M}$ Factor XIa in the presence of $7.5 \mu \mathrm{M} \alpha_{1}$-protease inhibitor. $a, 0.4 \mu \mathrm{M} ; b, 0.2 \mu \mathrm{M} ; c, 0.1$ $\mu \mathrm{M} ; \mathrm{d}, 0.04 \mu \mathrm{M} ; \mathrm{e}, 0 \mathrm{HMW}$ kininogen. (B) Conditions as in (A). Inhibitor, $5 \mu \mathrm{M}$ antithrombin III. $a, 0.4 \mu \mathrm{M} ; b, 0.2 \mu \mathrm{M} ; c, 0.1 \mu \mathrm{M} ; d, 0 \mathrm{HMW}$ kininogen. (C) Conditions as in (A). Inhibitor, $0.44 \mu \mathrm{M} \mathrm{Cl}$-inhibitor. $a, 0.4 \mu \mathrm{M} ; b, 0.2 \mu \mathrm{M} ; c, 0.1 \mu \mathrm{M} ; d, 0.04 \mu \mathrm{M} ; e, 0 \mathrm{HMW}$ kininogen.

mentally unproven, assumption that EC does not react appreciably with $I$. If this is so, a $K_{d}$ for the XIa-HMW kininogen complex can be calculated from Eq. 3, and is found to be $0.17 \pm 0.028 \mu \mathrm{M}$ SD in the presence of $\alpha_{1}$-protease inhibitor, $0.22 \pm 0.056 \mu \mathrm{M}$ in the presence of antithrombin III, and $0.19 \pm 0.07 \mu \mathrm{M}$ in the presence of $\mathrm{Cl}$-inhibitor. These data indicate the existence of a reversible XIa-HMW kininogen complex. As predicted, the $K_{d}$ is independent of the inhibitor concentration in the reaction.

Effect of LMW kininogen on Factor XIa inhibition. To ascertain which domain of the HMW kininogen molecule was responsible for the protective effect, LMW kininogen $(530 \mu \mathrm{g} / \mathrm{ml})$, which is similar to the heavy chain of HMW kininogen, was added to Factor XIa before addition of $\alpha_{1}$-protease inhibitor. No effect on the rate of inhibition, as compared to buffer, was observed, which suggests that the heavy chain of HMW kininogen was not responsible for the protective effect that was observed in Fig. 3.

Effect of $\mathrm{HMWK}_{L}$ on Factor XIa inhibition. $\mathrm{HMWK}_{\mathrm{L}}$ was added to Factor XIa before the addition of Cl-inhibitor at $23^{\circ} \mathrm{C}$ (Fig. 4). A striking decrease of the inactivation rate of Factor XIa was observed. A $K_{d}$ of $0.086 \mu \mathrm{M}$ was calculated for the Factor XIa$\mathrm{HMWK}_{\mathrm{L}}$ complex, which indicates that $\mathrm{HMWK}_{\mathrm{L}}$ protects Factor XIa from inhibitors via complex formation, and that $\mathrm{HMWK}_{\mathrm{L}}$ has a greater affinity for Factor XIa than does intact HMW kininogen.

Relative contribution of plasma protease inhibitors of Factor XIa. The relative contribution of plasma protease inhibitors against Factor XIa was calculated by first determining the $k^{\prime \prime}$ for each inhibitor at $37^{\circ} \mathrm{C}$, and then multiplying that value by the plasma concentration of each inhibitor, previously tabulated by Harpel (33) (Table I), using the equation $k^{\prime}=k^{\prime \prime}(\mathrm{I})$. The values for $k^{\prime}$ were tabulated for $\alpha_{1}$-protease inhibitor, antithrombin III, and C1-inhibitor from this study, and for $\alpha_{2}$-plasmin inhibitor from the report of Saito et al. (7). From these data we predicted that $\alpha_{1}$-protease inhibitor would be responsible for $68 \%$ of the inhibitory activity in plasma against Factor XIa. Antithrombin III was estimated to be responsible for $16 \%$, and $\mathrm{Cl}$-inhibitor and $\alpha_{2}$-plasmin inhibitor were each responsible for $8 \%$ of the total inhibitory activity against Factor XIa.

Although the rate of inhibition was increased approximately threefold at $37^{\circ} \mathrm{C}$, as compared to $23^{\circ} \mathrm{C}$, similar results were obtained for the relative contribution of inhibitors when the $k^{\prime}$ was calculated from data derived at either temperature (Table I). In agreement with Harpel (8), no inhibition by $\alpha_{2}$-macroglobulin, another major protease inhibitor, was noted at a concentration of $200 \mu \mathrm{g} / \mathrm{ml}$, nor did $\alpha_{2}$-macroglobulin protect Factor XIa from inhibition by $\alpha_{1}$-protease inhibitor. These data indicate that $\alpha_{1}$-protease inhibitor is the major inhibitor of Factor XIa at plasma concentration.

Inactivation of Factor XIa by plasma. To test this hypothesis, we measured the inhibition of Factor XIa at $23^{\circ} \mathrm{C}$ by normal plasma, as well as by plasma samples deficient in various inhibitors or in HMW kini- 


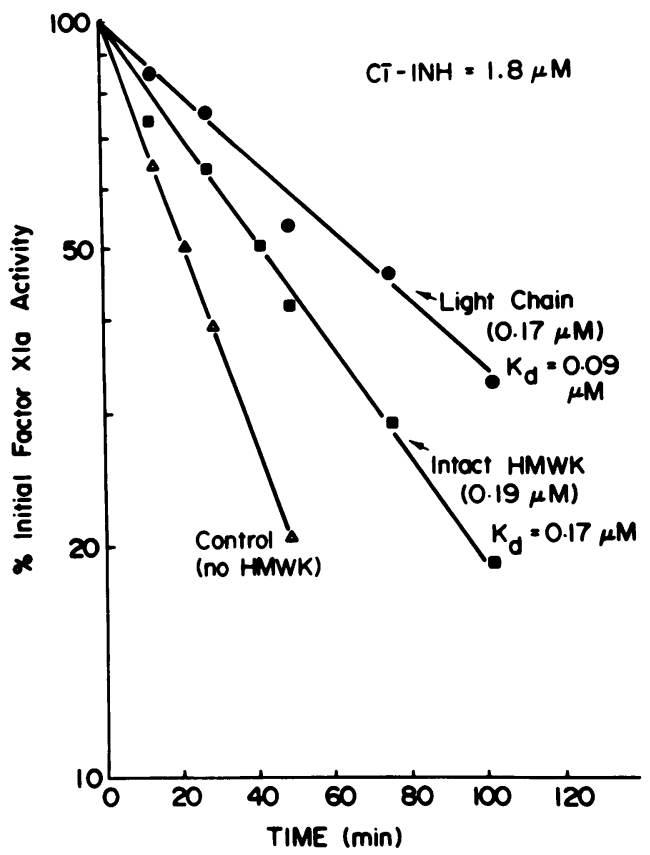

Figure 4 Effect of $\mathrm{HMWK}_{\mathrm{L}}$ on the inactivation rate of Factor XIa by $\mathrm{Cl}$-inhibitor. XIa $(0.03 \mu \mathrm{M})$ was incubated with $\mathrm{Cl}$-inhibitor $(1.8 \mu \mathrm{M})$ in the presence and absence of either $\mathrm{HMWK}_{\mathrm{L}}(0.17 \mu \mathrm{M})$ or intact HMK kininogen $(0.19$ $\mu \mathrm{M})$ at $23^{\circ} \mathrm{C}$.

nogen at a final dilution of plasma equal to 1:7.5 (Fig. 5). HMW kininogen-deficient plasma exhibited a $20 \%$ increase in the inhibitory activity of normal plasma against Factor XIa under the conditions employed. $\alpha_{1}$-protease inhibitor-deficient plasma, which contained $20 \%$ of normal $\alpha_{1}$-protease activity, exhibited only $53 \%$ of the inhibitory capacity of normal plasma.

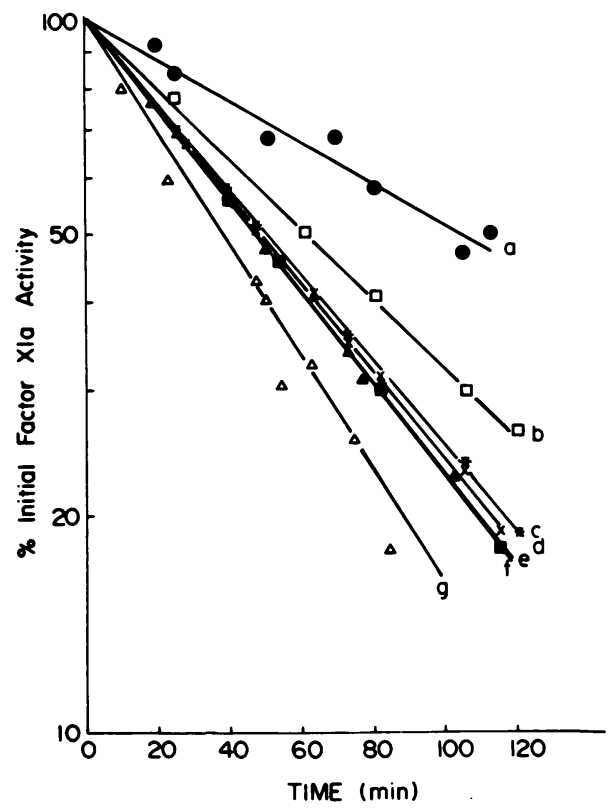

Figure 5 Inactivation of Factor XIa by Plasma. Factor XIa $(0.03 \mu \mathrm{M})$ was incubated with $20 \mu \mathrm{l}$ of various plasma samples at $23^{\circ} \mathrm{C}$ in a final volume of $150 \mu \mathrm{l}$, as follows: a, $\alpha_{1}{ }^{-}$ protease inhibitor deficient (20\% of normal) (๑); b, antithrombin III deficient ( $\square)$; c, $\alpha_{2}$-plasmin inhibitor deficient $\left(^{\circ}\right)$; d, Factor XI deficient $(X)$; e, normal pooled plasma $(\triangle)$; f, Cl-inhibitor deficient ( $\square)$; g, HMW kininogen deficient $(\Delta)$.

The antithrombin III-deficient plasma demonstrated $80 \%$ of normal inhibitory capacity. Cl-inhibitor-deficient plasma showed $95 \%$ of normal activity and $\alpha_{2}$ plasmin-inhibitor-deficient plasma was virtually identical to normal plasma (Table II). Therefore, $\alpha_{1}$-protease inhibitor is the major inhibitor of Factor XIa in

TABLE I

Relative Contribution of Plasma Protease Inhibitors of Factor XIa

\begin{tabular}{lccccc}
\hline \multicolumn{1}{c}{ Inhibitor } & Temperature & $k^{*}$ & [I]t & $k^{\prime} 8$ & $\begin{array}{c}\text { Percentage } \\
\text { of total }\end{array}$ \\
\hline & ${ }^{\circ} \mathrm{C}$ & $\boldsymbol{M}^{-1} \mathrm{~min}^{-1}$ & $\mu M$ & $\min ^{-1}$ & \\
$\alpha_{1}$-Antitrypsin & 37 & $1.3 \times 10^{4}$ & 45.5 & 0.59 & 68 \\
$\alpha_{1}$-Antitrypsin & 23 & $0.4 \times 10^{4}$ & 45.5 & 0.18 & 65 \\
Antithrombin III & 37 & $3.0 \times 10^{4}$ & 4.7 & 0.14 & 16 \\
Antithrombin III & 23 & $1.0 \times 10^{4}$ & 4.7 & 0.047 & 17 \\
Cl-Inhibitor & 37 & $4.0 \times 10^{4}$ & 1.7 & 0.068 & 8 \\
Cl-Inhibitor & 23 & $1.5 \times 10^{4}$ & 1.7 & 0.025 & 9 \\
$\alpha_{2}$-Plasmin inhibitor & 37 & $6.0 \times 10^{411}$ & 1.1 & 0.066 & 8 \\
$\alpha_{2}$-Plasmin inhibitor & 23 & $2.3 \times 10^{4} \pi$ & 1.1 & 0.025 & 9 \\
\hline
\end{tabular}

- Second-order rate constant at either 37 or $23^{\circ} \mathrm{C}$.

† Plasma inhibitor concentration (31).

\$ Pseudo-first-order reaction rate derived by multiplying the $k^{\prime \prime}$ by [I].

"From Saito et al. (7).

I On the assumption that the $k^{\prime}$ is equal to the $k^{\prime}$ for $\mathrm{Cl}$-inhibitor (7). 
TABLE II

Inhibition of Factor XIa by Plasma Deficient in Protease Inhibitors or HMW Kininogen

\begin{tabular}{lcc}
\hline \multicolumn{1}{c}{ Deficient plasma } & $\begin{array}{c}\text { Predicted inhibitory } \\
\text { activity }\end{array}$ & $\begin{array}{c}\text { Observed inhibitory } \\
\text { activity }\end{array}$ \\
\hline & & $\%$ \\
$\alpha_{1}$-Antitrypsin deficient (20\% of normal) 1 & 48 & 53 \\
Antithrombin III deficient & 83 & 80 \\
Cl-Inhibitor deficient (<5\% of normal) $\downarrow$ & 91 & 95 \\
$\alpha_{2}$-Plasmin inhibitor deficient & 91 & 100 \\
HMW kininogen deficient & 118 & 120 \\
\hline
\end{tabular}

- The inhibitory activity was measured in plasma diluted 1:7.5 (see Fig. 6).

\$ Normal pooled plasma used as a reference.

plasma, in agreement with the conclusions of Heck and Kaplan (6).

\section{DISCUSSION}

In this study, we have investigated the quantitative contribution of each inhibitor of Factor XIa, both in purified systems as well as in plasma. $\alpha_{1}$-protease inhibitor, antithrombin III, and Cl-inhibitor each inhibited Factor XIa coagulant activity while exhibiting pseudo-first-order kinetics when present in a 10- to 100 -fold molar excess. No kinetically demonstrable reversible enzyme-inhibitor complex was observed, similar to the mechanism that we recently reported for the inhibition of kallikrein by Cl-inhibitor (13). It is possible, however, that more rapid detection methods, necessitated by high inhibitor concentrations, might reveal the existence of a transient complex.

The results of the inhibition of Factor XIa by various diluted plasma samples agreed well with our predicted values calculated from the inhibition of Factor XIa in a purified system (Table II). It therefore appears that the existence of another major Factor XIa inhibitor can ive ruled out.

In addition to the role of each inhibitor, it is necessary to consider the influence of HMW kininogen on the inactivation rate of Factor XIa. HMW kininogen decreased the rate of inactivation of Factor XIa by each inhibitor tested, similar to what we observed with kallikrein inhibition (13). Kinetically, the complex of Factor XIa and HMW kininogen is more resistant to the effect of inhibitors than uncomplexed XIa. In agreement with the results in a purified system is the observation of increased inhibition of Factor XIa by kininogen-deficient plasma. It can be calculated from the data in diluted plasma that HMW kininogen would reduce the rate of inactivation of XIa in undiluted plasma by $80 \%$, since the $K_{\mathrm{d}} \cong 0.17 \mu \mathrm{M}$ and the plasma concentration of HMW kininogen is $0.75 \mu \mathrm{M}$.
The site of complex formation on the HMW kininogen molecule was also probed. HMW kininogen $\left(M_{\mathrm{r}}=110,000\right)$ is cleaved by kallikrein into a heavy chain $\left(M_{\mathrm{r}}=65,000\right)$ and a light chain $\left(M_{\mathrm{r}}=45,000\right)$ with the release of the peptide bradykinin $\left(M_{\mathrm{r}}=1,500\right)$ from the heavy chain $(24,34)$. Upon reduction, the two polypeptide chains are separated. LMW kininogen, which is antigenically similar to the heavy chain of HMW kininogen, and does not exhibit coagulant activity (35), did not modulate the inhibition of Factor XIa. In contrast, the light chain, which contains the coagulant activity of HMW kininogen $(24,35)$, as well as a binding site for Factor XI (34), decreased the rate of inhibition of Factor XIa by $\alpha_{1}$-protease inhibitor. Therefore, the light chain domain of HMW kininogen is involved in complex formation.

The dissociation constant for the Factor XIa-HMW kininogen complex was found to be $0.17 \mu \mathrm{M}$, which is lower than $0.75 \mu \mathrm{M}$ determined for the kallikreinHMW kininogen complex (13). These results are qualitatively similar to those of Thompson et al. (35), who found a lower dissociation constant for Factor XIHMW kininogen $(0.002 \mu \mathrm{M})$ than for prekallikreinHMW kininogen $(0.028 \mu \mathrm{M})$. The large difference in $K_{d}$ between the data of Thompson et al. (35) and our present data may be due to either a higher affinity of HMW kininogen for the zymogens in that study than for the enzymes in our study. Alternatively, it may reflect the difference between functional kinetic determinations in the fluid-phase vs. physical binding measured in the presence of a plastic surface (36). The affinity of the proteins itself for the surface especially at low concentrations (37) might lead to lower calculated dissociation constants. It is noteable that binding of Factor XIa to the light chain of HMW kininogen $\left(K_{\mathrm{d}}=0.086 \mu \mathrm{M}\right)$ is tighter than to the intact HMW kininogen molecule $\left(K_{\mathrm{d}}=0.17 \mu \mathrm{M}\right)$. This indicates that the heavy chain of HMW kininogen may sterically interfere with access of Factor XIa to the light chain 
of HMW kininogen. Similar results have been noted for complexes between the $\mathrm{HMWK}_{\mathrm{L}}$ and kallikrein (38).

The regulation of the inhibition of Factor XIa and kallikrein greatly differs. The second-order rate constant for the inhibition of Factor XIa by each of its plasma protease inhibitors is very similar. Therefore, it is only the concentration of each inhibitor in plasma that dictates which will be the most effective inhibitor of Factor XIa. This observation contrasts with the $k^{\prime \prime}$ that was calculated for each inhibitor of kallikrein (38). The reaction of kallikrein and Cl-inhibitor is 5,000fold greater than the $k^{\prime \prime}$ for the reaction of kallikrein and $\alpha_{1}$-protease inhibitor. In contrast, as previously observed (6), $\alpha_{1}$-protease inhibitor is the major inhibitor of Factor XIa. Quantitatively it accounts for $68 \%$ of the inhibitory activity of plasma, whereas C1-inhibitor, a major inhibitor of kallikrein, accounts for only $8 \%$ of the inhibitory activity of Factor XIa. $\alpha_{2}$ macroglobulin, the other major inhibitor of kallikrein, does not inhibit Factor XIa. Although the $k^{\prime}$ for the inhibition of kallikrein by $\mathrm{Cl}$-inhibitor, at plasma concentration of Cl-inhibitor, is 10 times greater than the $k^{\prime}$ for Factor XIa- $\alpha_{1}$-protease inhibitor complex at the plasma concentration of $\alpha_{1}$-protease inhibitor, HMW kininogen protects Factor XIa fourfold more effectively than it protects kallikrein against inactivation.

Antithrombin III accounts for $17 \%$ of the plasma inhibitory activity against Factor XIa. Damus et al. (5) have reported that heparin greatly accelerates the inactivation rate of Factor XIa by antithrombin III, suggesting the possibility that in the presence of heparin, antithrombin III might become the major inhibitor in plasma of Factor XIa. Since Busch and Owen (39) have recently found that the vascular endothelium catalyzes the thrombin-antithrombin III reaction in a manner analogous to free heparin; it is possible that the major inhibitor of Factor XIa in vivo is antithrombin III bound to the endothelium. However, we have recently demonstrated (40) using both amidolytic and coagulant assays in purified systems and plasma that heparin $(1 \mathrm{U} / \mathrm{ml})$ failed to accelerate the inactivation rate of Factor XIa while dramatically increasing the inhibition of thrombin. Thus, it appears unlikely that antithrombin III plays a major inhibitory role in plasma against Factor XIa.

Since both Factor XI and prekallikrein are activated by the same enzyme (Factor XIIa) in the presence of the same cofactor (HMW kininogen), it is clear that both the differential effect of plasma protease inhibitors on the two enzymes and the quantitative differences in the protection offered by HMW kininogen may serve as major regulators of these enzymes in plasma. Variations in enzyme, inhibitor, or HMW kininogen concentration may direct the contact system, after Factor XII activation, toward coagulation via
Factor XIa, or toward fibrinolysis and vasodilation via kallikrein action.

Finally, $\alpha_{1}$-protease inhibitor is usually considered an inhibitor of tissue proteases such as elastase and trypsin. A role for this inhibitor in plasma, where it accounts for almost $5 \%$ of the total plasma protein, is not surprising. It is possible that in the familial deficiency of $\alpha_{1}$-protease inhibitor, or in the acquired deficiency of that inhibitor resulting from smoking cigarettes $(41,42)$, the decrease of inhibition of Factor XIa could result in the localized fibrin formation that might play a role in the pulmonary diseases associated with this deficiency.

\section{ACKNOWLEDGMENTS}

We thank Dr. M. Wickerhauser, American Red Cross, Bethesda, MD, for providing partially purified Cl-inhibitor, and Dr. H. Saito, Case Western Reserve, Cleveland, $\mathrm{OH}$, for providing $\alpha_{2}$ PI-deficient plasma. We are grateful to Dr. Linda Knight for radiolabeling the purified Factor XIa, to Lee D. Silver for preparing HMW kininogen and its light chain, and to Dr. John Holt for preparing heparin-agarose.

\section{REFERENCES}

1. Kurachi, K., and E. W. Davie. 1977. Activation of human Factor XI (plasma thromboplastin antecedent) by Factor XIla (activated Hageman factor). Biochemistry. 16: 5831-5839.

2. Bouma, B. N., and J. H. Griffin. 1977. Human blood coagulation Factor XI: purification properties and mechanism of activation. J. Biol. Chem. 252: 6432-6437.

3. Schiffman, S., R. Pecci, and P. Lee. 1977. Contact activation of Factor XI: evidence that the primary role of contact activation cofactor (CAC) is to facilitate the activation of Factor XII. Thromb. Res. 1: 319-323.

4. Forbes, C. D., J. Pensky, and O. D. Ratnoff. 1970. Inhibition of activated Hageman factor and activated plasma thromboplastin antecedent by purified $\mathrm{Cl}$-inactivator. J. Lab. Clin. Med. 76: 809-815.

5. Damus, P. S., M. Hicks, and R. D. Rosenberg. 1973. Anticoagulant activity of heparin. Nature (Lond.). 246: 355-357.

6. Heck, L. W., and A. P. Kaplan. 1974. Substrates of Hageman factor. I. Isolation and characterization of human Factor XI (PTA) and inhibition of the activated enzyme by $\alpha_{1}$-antitrypsin. J. Exp. Med. 140: 1615-1630.

7. Saito, H., G. H. Goldsmith, M. Moroi, and N. Aoki. 1979. Inhibitory spectrum of $\alpha_{2}$-plasmin inhibitor. Proc. Natl. Acad. Sci. U. S. A. 76: 2013-2017.

8. Harpel, P. C. 1971. Separation of plasma thromboplastin antecedent from kallikrein by the plasma $\alpha_{2}$-macroglobulin kallikrein inhibitor. J. Clin. Invest. 50: 2084-2090.

9. Thompson, R. E., R. Mandle, Jr., and A. P. Kaplan. 1977. Association of Factor XI and high molecular weight kininogen in human plasma. J. Clin. Invest. 60: 13761380 .

10. Mandle, R., Jr., R. W. Colman, and A. P. Kaplan. 1976. Identification of prekallikrein and high molecular weight kininogen as a complex in human plasma. Proc. Natl. Acad. Sci. U. S. A. 73: 4179-4183.

11. Scott, C. F., and R. W. Colman. 1980. Function and immunochemistry of prekallikrein-high molecular weight kininogen complex in plasma. J. Clin. Invest. 65: 413421. 
12. Kerbiriou, D. M., B. N. Bouma, and J. H. Griffin. 1980. Immunochemical studies of human high molecular weight kininogen and of its complexes with plasma prekallikrein or kallikrein. J. Biol. Chem. 255: 3952-3958.

13. Schapira, M., C. F. Scott, and R. W. Colman. 1981. Protection of human plasma kallikrein from inactivation by $\mathrm{Cl}$-inhibitor and other protease inhibitors. The role of high molecular weight kininogen. Biochemistry. 20: 2738-2743.

14. Colman, R. W., A. Bagdasarian, R. C. Talamo, C. F. Scott, M. Seavey, J. A. Guimaraes, J. V. Pierce, and A. P. Kaplan. 1975. Williams trait. Human kininogen deficiency with diminished levels of plasminogen proactivator and prekallikrein associated with abnormalities of the Hageman factor-dependent pathways. J. Clin. Invest. 56: 1650-1662.

15. Colman, R. W., R. Edelman, C. F. Scott, and R. M. Gilman. 1978. Plasma kallikrein activation in typhoid fever. J. Clin. Invest. 61: 287-296.

16. Schapira, M., L. D. Silver, C. F. Scott, and R. W. Colman. 1982. New and rapid functional assay for $C \bar{l}$ inhibitor in plasma. Blood. In press.

17. Walsh, K. A., and P. E. Wilcox. 1970. Serine proteases. Methods Enzymol. 19: 31-41.

18. Thaler, E., and G. Schmer. 1975. A simple two-step isolation procedure for human and bovine antithrombin II/ III (heparin cofactor): a comparison of two methods. $\mathrm{Br}$. J. Haematol. 31: 233-243.

19. Cohen, A. B., and H. L. James. 1978. Evaluation of alpha-1-antitrypsin as a potential therapeutic agent. In Proceedings of the International Workshop on Technology for Protein Separation and Improvement of Blood Plasma Fractionation. H. E. Saudberg, editor. Department of Health, Education, and Welfare Publication No. (NIH) 78-14222. U. S. Government Printing Office, Washington, D. C. 326-338.

20. Lo, T. N., A. B. Cohen, and H. L. James. 1976. The interaction of $\alpha_{1}$-antitrypsin with soluble and Sepharosebound elastase. Biochim. Biophys. Acta. 453: 344-356.

21. Laemmli, U. K., 1970. Cleavage of the structural proteins during assembly of the head of the bacteriophage T4. Nature (Lond.). 227: 680-685.

22. Wickerhauser, M., Y. L. Hao, and J. Mercer. 1978. Method for large-scale preparation of $\mathrm{Cl}$-inactivator concentrate for clinical studies. Joint Congress of the International Societies of Hematology and Blood Transfusion, Paris, France. 483. (Abstr.)

23. Levy, L. R, and I. H. Lepow. 1959. Assay and properties of serum inhibition of $C^{\prime} 1$ esterase. Proc. Soc. Exp. Biol. Med. 101: 608-611.

24. Kerbiriou, D. M., and J. H. Griffin. 1979. Human high molecular weight kininogen. Studies on structure-function relationships and of proteolysis of the molecule occurring during the contact activation of plasma. J. Biol. Chem. 254: 12020-12027.

25. Lowry, O. H., N. J. Rosebrough, A. L. Farr, and R. J. Randall. 1951. Protein measurement with the Folin phenol reagent. J. Biol. Chem. 193: 265-275.

26. Weber, K., and M. Osborn. 1969. The reliability of molecular weight determination by dodecyl sulfate-polyacrylamine gel electrophoresis. J. Biol. Chem. 244: 4406-4412.

27. Scott, C. F., C. Y. Liu, and R. W. Colman. 1979. Human plasma prekallikrein: a rapid high yield method for purification. Eur. J. Biochem. 100: 77-83.

28. Habal, F. M., H. Z. Movat, and C. E. Burrowes. 1974 Isolation of two functionally different kininogens from human plasma separation from proteolytic inhibitors and interaction with plasma kallikrein. Biochem. Pharmacol. 23: 2291-2302.

29. Mannhalter, C., S. Schiffman, and A. Jacobs. 1979. Trypsin activation of human factor XI. J. Biol. Chem. 255: 2667-2669.

30. Bolton, A. E., and W. M. Hunter. 1973. The labelling of proteins to high specific radioactivity by conjugation to a ${ }^{125}$ I-containing acylating agent. Biochem. J. 133: 529-539.

31. Proctor, R. R., and S. I. Rapaport. 1961. The partial thromboplastin time with kaolin: the simple screening test for the first stage plasma clotting factor deficiencies. Am. J. Clin. Pathol. 36: 212-219.

32. Kitz, R., and I. B. Wilson. 1962. Esters of methanesulfonic acid as irreversible inhibitors of acetylcholinesterase. J. Biol. Chem. 237: 3245-3249.

33. Harpel, P. C. 1982 . Blood proteolytic enzyme inhibitors: their role in modulating blood coagulation and fibrinolytic enzyme pathways. In Hemostasis and Thrombosis: Basic Principles and Clinical Practice R. W. Colman, J. Hirsh, V. Marder, and E. W. Salzman, editors. In press.

34. Wuepper, K. 1972. Biochemistry and biology of components of the plasma kinin-forming system. In Inflammation, Mechanisms and Control. 93-117.

35. Thompson, R. E., R. Mandle, Jr., and A. P. Kaplan. 1978. Characterization of human high molecular weight kininogen. Procoagulant activity associated with the light chain of kinin-free high molecular weight kininogen. $J$. Exp. Med. 147: 488-499.

36. Thompson, R. E., R. Mandle, Jr., and A. P. Kaplan. 1979. Studies of binding of prekallikrein and Factor XI to high molecular weight kininogen and its light chain. Proc. Natl. Acad. Sci. U. S. A. 76: 4862-4866.

37. Scott, C. F., Kirby, E. P., Schick, P. K., and Colman, R. W. 1981. Effect of surfaces on fluid-phase prekallikrein activation. Blood. 57: 553-560.

38. Schapira, M., C. F. Scott, A. James, L. D. Silver, F. Kueppers, H. L. James, and R. W. Colman. 1982. High molecular weight kininogen or its light chain protects human plasma kallikrein from inactivation by plasma protease inhibitors. Biochemistry. In press.

39. Busch, P. G., and Owen, W. G. 1981. Identification of a cell surface cofactor for antithrombin III on cultured murine endothelium. Thromb. Haemostasis. 46: 38.

40. Scott, C. F., Schapira, M., and Colman, R. W. 1982. Effect of heparin on the inactivation rate of human factor XIa by antithrombin III. Fed. Proc. 41. In press.

41. Janoff, A., and H. Carp. 1977. Possible mechanism of emphysema in smokers. I. Cigarette smoke condensate suppresses protease inhibition in vitro. Am. Rev. Respir. Dis. 116: 65-72.

42. Carp, H., and A. Janoff. 1978. Possible mechanisms of emphsyema in smokers: in vitro suppression of serum elastase-inhibitory capacity by fresh cigarette smoke and its prevention by antioxidants. Am. Rev. Respir. Dis. 118: 617-621. 